\title{
Phylogenetic Relationships of Tetraploid AB-Genome Avena Species Evaluated by Means of Cytogenetic (C-Banding and FISH) and RAPD Analyses
}

\author{
E. D. Badaeva, ${ }^{1,2}$ O. Yu. Shelukhina, ${ }^{2}$ S. V. Goryunova, ${ }^{2}$ I. G. Loskutov, ${ }^{3}$ and V. A. Pukhalskiy ${ }^{2}$ \\ ${ }^{1}$ Engelhardt Institute of Molecular Biology, Russian Academy of Sciences, Vavilov str. 32, Moscow 119991, Russia \\ ${ }^{2}$ N.I. Vavilov Institute of General Genetics, Russian Academy of Sciences, Gubkin str. 3, Moscow 119991, Russia \\ ${ }^{3}$ N.I. Vavilov Institute of Plant Industry (VIR), Russian Academy of Agricultural Sciences, Bolshaya Morskaya str. 44, \\ St. Petersburg 190000, Russia
}

Correspondence should be addressed to E. D. Badaeva, katerinabadaeva@gmail.com

Received 10 December 2009; Revised 11 February 2010; Accepted 15 March 2010

Academic Editor: Kang Chong

Copyright ( 2010 E. D. Badaeva et al. This is an open access article distributed under the Creative Commons Attribution License, which permits unrestricted use, distribution, and reproduction in any medium, provided the original work is properly cited.

\begin{abstract}
Tetraploid oat species Avena abyssinica, A. vaviloviana, A. barbata, and A. agadiriana were studied using C-banding technique, in situ hybridization with the $45 \mathrm{~S}$ and $5 \mathrm{~S}$ rDNA probes, and RAPD analysis in comparison with the diploid species carrying different types of the A-genome (A. wiestii, As; A. longiglumis, Al; A. canariensis, Ac; A. damascena, Ad, A. prostrata, Ap). The investigation confirmed that all four tetraploids belong to the same AB-genome group; however A. agadiriana occupies distinct position among others. The C-banding, FISH, and RAPD analyses showed that Avena abyssinica, A. vaviloviana, and A. barbata are very similar; most probably they originated from a common tetraploid ancestor as a result of minor translocations and alterations of C-banding polymorphism system. AB-genome species are closely related with the A-genome diploids, and an As-genome species may be regarded as the most probable donor of their A-genome. Although their second diploid progenitor has not been identified, it seems unlikely that it belongs to the As-genome group. The exact diploid progenitors of A. agadiriana have not been determined; however our results suggest that at least one of them could be related to A. damascena.
\end{abstract}

\section{Introduction}

Tetraploid oats are subdivided into four groups on the basis of karyotype structure and meiotic analysis of interspecific hybrids. We have focused on the two groups. The first of these has an $\mathrm{AB}$-genome composition and includes $\mathrm{A}$. barbata Pott., A. vaviloviana Mordv., and A. abyssinica Hochst. [1]. These three species hybridize with each other as well as with other Avena L. species, with the exception of those possessing the C-genome [2]. Some authors believe that this group originated through chromosome duplication of the As-genome diploid progenitor (possibly, A. hirtula Lagas. or A. wiestii Steud.) [3-6] and accordingly, the B-genome is a product of modification of the A-genome [7]. Therefore, the genome formula $\mathrm{AA}^{\prime}$ was suggested for this group [8-10].

Another possibility is that the $\mathrm{AB}$-genome oats are allopolyploids originated from hybridization of two different $\mathrm{A}$-genome species, and therefore, the $\mathrm{A}$ and $\mathrm{B}$ genomes are genetically distinct $[1,11]$. This assumption was confirmed by the results of molecular and cytogenetic analyses. They showed that the DNA sequence $p A s 120 a$, which is characteristic of the As-and Al-genome diploids, is hybridized only on the A-genome chromosomes, but not on the B-genome chromosomes of $A$. barbata and A. vaviloviana as well as on the chromosomes of $A$. canariensis and A. damascena [12].

The second group includes a single species, A. agadiriana Baum et Fedak. First, it was found during examination of a collection of the diploid A. canariensis, and based on morphological similarity this species was regarded as the progenitor of A. agadiriana. However, analysis of chromosome pairing in hybrids, which showed that at least four translocations are required for the formation of the multivalent associations in hybrids contradicted this suggestion [13]. Furthermore, the natural areas of these species do not overlap $[14,15]$. 
When analyzing the results of hybridization of A. agadiriana with other Avena species, Leggett [13] found that it has a higher affinity for A. barbata than any other tetraploid Avena species and accordingly, he placed it in the AB-genome group. AFLP analysis of 25 Avena species revealed similarity between $A$. agadiriana and $A$. abyssinica [16]. Assessment of genetic relationships among 25 taxa of the genus Avena using consensus chloroplast simple repeat (ccSSR) markers confirmed affiliation of $A$. agadiriana with the AB-genome tetraploids [17]. Relatedness of these species was also shown by Southern blot hybridization of $A$. agadiriana genomic DNA with the C-genome specific sequence probes $R S-1$ and rDNA [18]. The authors concluded that $A$. agadiriana does not contain the $\mathrm{C}$-genome. At the same time, A. agadiriana shares some morphological similarities with the AC(DC)genome tetraploids A. magna and A. murphyi as well as several hexaploid oats. In addition, it crosses easily with hexaploids which may suggest that $A$. agadiriana participated in hexaploid evolution [19].

\section{Materials and Methods}

2.1. Plant Material. The materials were obtained from the oat germplasm collections of the Vavilov Institute of Plant Industry (VIR), St. Petersburg, Russia and Plant Gene Resources of Canada (PGRC), Saskatoon, Canada. Twenty four accessions of $A$. abyssinica, A. barbata, A. vaviloviana, $A$. agadiriana and one accession each of diploid $A$. strigosa (As-genome), A. longiglumis (Al-genome), A. canariensis (Ac-genome), and A. damascena (Ad-genome) were studied using C-banding (Table 1). RAPD analysis was performed on 45 accessions. Thirty of these represented the ABgenome group, and the remaining 15 represented each of the diploid and polyploid Avena species with different genome constitutions (Table 1). Four accessions representing each tetraploid AB-genome species and six accessions of diploid species representing different types of the A-genome were used in FISH analysis.

2.2. RAPD-Analysis. Genomic DNA was isolated from young plants according to the protocol of [20], with the modifications of [21]. The polymerase chain reaction (PCR) was carried out with a kit (Dialat, LTD, Moscow) using nine standard oligonucleotide primers («Operon Biotechnologies», Germany), that were preliminarily scored and tested on other cereal species: OPA9, OPD1, OPD6, OPD12, OPK10, OPN1, OPN13, OPN15, OPN19 [22, 23].

DNA was amplified in a reaction mix (final volume $15 \mu \mathrm{L}$ ) containing $1 \times$ buffer from the respective kit, $1.5 \mu \mathrm{M}$ of $\mathrm{MgCl}_{2}, 0.2 \mathrm{mM}$ of each dNTP, $0.5 \mu \mathrm{M}$ of primers, 1 unit of Taq polymerase, and $100 \mathrm{ng}$ of genomic DNA. Amplification was carried out in a "MJResearch P-100" (USA) Thermocycler with preliminary denaturation at $94^{\circ} \mathrm{C}$ for 5 minutes followed by 36 cycles: $94^{\circ} \mathrm{C}$ for 40 seconds, $37^{\circ} \mathrm{C}$ for 40 seconds, $72^{\circ} \mathrm{C}$ for 1 minute, and a final extension at $72^{\circ} \mathrm{C}$ for 10 minutes. Amplification products were separated in $1.7 \%$ agarose gels in $1 \mathrm{x}$ TBE buffer, stained with ethidium bromide and photographed.
Only clear and reproducible bands were used for binary matrix construction. Genetic similarities were calculated using the Jaccard (1908) coefficient. Dendrograms were generated with UPGMA (Unweighted Pair Group Method with Arithmetic mean). In addition, the results of RAPD were analyzed using Principal Coordinate Analysis (PCO). Statistical analysis was performed in the program PAST (Hammer et al. 2001).

2.3. C-Banding. Chromosome preparation and C-banding procedure were carried out according to [24]. The slides were analyzed on the Leitz Wetzlar microscope, and the selected metaphase plates were captured (magnification $100^{\mathrm{x}}$ ) using a CCD camera Leica DFC 280.

2.4. DNA Clones. Two clones of ribosomal RNA gene families were used for in situ hybridization. The clone pTa794 is a $410 \mathrm{bp} \mathrm{BamH1-fragment} \mathrm{of} \mathrm{5S} \mathrm{rDNA} \mathrm{of} \mathrm{wheat,} \mathrm{inserted}$ into the pBR322 plasmid [25]. The clone pTa71 is the EcoRI fragment of 45S rRNA gene of wheat with the length of $9 \mathrm{~kb}$ subcloned in the pUC19 plasmid [26]. The probes were labeled with biotin or digoxigenin by nick translation using the appropriate kits (Roche, Germany) according to manufacturer's protocol.

2.5. Fluorescence In Situ Hybridization (FISH). In situ hybridization and signal detection were carried out according to [27]. The slides were analyzed on a Zeiss Imager D1 microscope. Metaphase plates were photographed at magnification $100^{\mathrm{x}}$ with a black and white digital camera Axiocam HRm using a software AxioVision, release 4.6.

\section{Results}

To clarify the phylogenetic relationships in the group of tetraploid AB-genome oats and to evaluate the level of intraspecific polymorphism in each species, a comparative study of $A$. barbata, A. vaviloviana, A. abysinica, and A. agadiriana was carried out using C-banding method supplemented with in situ hybridization with the $5 \mathrm{~S}$ and $18 \mathrm{~S}$ $26 \mathrm{~S}$ rRNA gene probes and the RAPD technique. Three to fourteen accessions were examined for each species.

Three tetraploid oat species, A. abyssinica, A. barbata, and $A$. vaviloviana were similar with respect of chromosome structure and C-banding patterns (Figures 1(a), 1(b), 1(d)). Their karyotypes were characterized by low heterochromatin content; small or medium-sized blocks were found in the pericentromeric, telomeric, and occasionally in intercalary regions of chromosomes (Figures 2, 3(a)-3(j)), similarly to the A-genome diploid (Figure 4 ) oat species. Seven chromosome pairs of A. abyssinica, A. barbata, and A. vaviloviana resembled chromosomes of the As-genome diploids in morphology and C-band distribution (Figure 4, As). They were assigned to the A-genome and classified according to nomenclature of A. strigosa chromosomes [28]. Other chromosomes, presumed to belong to the B-genome, were ranked in descending order of their length. 
TABLe 1: The list of studied accessions of Avena and their origins.

\begin{tabular}{|c|c|c|c|c|}
\hline Species (genome formula) & Designation in RAPD (Figures 4-6) & Catalogue \# & Country of origin & Source \\
\hline A. eriantha $(\mathrm{Cp})$ & $\mathrm{pl}$ & $\mathrm{CN} 19329^{2}$ & Algeria & PGRC \\
\hline A. clauda $(\mathrm{Cp})$ & $\mathrm{cl}$ & $\mathrm{CN} 19207^{2}$ & Iran & PGRC \\
\hline A. ventricosa $(\mathrm{Cv})$ & vt & CN21405 & Algeria & PGRC \\
\hline A. longiglumis (Al) & $\lg$ & $\begin{array}{l}\mathrm{k}-1881 \\
\mathrm{k}-1810\end{array}$ & unknown, obtained from USA & VIR \\
\hline A. damascena (Ad) & $\mathrm{dm}$ & CN19459 & Syria & PGRC \\
\hline A. prostrata (Ap) & pr & $\mathrm{k}-2055^{2}$ & Spain & VIR \\
\hline A. wiestii (As) & $\mathrm{w}$ & $\mathrm{k}-94$ & Egypt & VIR \\
\hline A. hirtula (As) & ht & k-2031 & Sicily & VIR \\
\hline A. atlantica (As) & at & CN25895 & Morocco & PGRC \\
\hline A. strigosa (As) & st & k-5244 & Portugal & VIR \\
\hline A. canariensis (Ac) & $\mathrm{cn}$ & $\mathrm{k}-293$ & Spain, Canary Island & VIR \\
\hline \multirow{6}{*}{ A. abyssinica (AB) } & al & $\mathrm{k}-4972^{1}$ & Ethiopia & VIR \\
\hline & a2 & k-4978 & Ethiopia & VIR \\
\hline & a3 & k-5107 & Ethiopia & VIR \\
\hline & $\mathrm{a} 4$ & k-14819 & Ethiopia & VIR \\
\hline & a5 & $\mathrm{k}-14826$ & Ethiopia & VIR \\
\hline & a6 & $\mathrm{k}-11678^{2}$ & Ethiopia & VIR \\
\hline \multirow{18}{*}{ A. barbata $(\mathrm{AB})$} & b1 & $\mathrm{k}-316$ & Azerbaijan & VIR \\
\hline & b2 & k-1920 & Israel & VIR \\
\hline & b3 & $\mathrm{k}-230$ & Azerbaijan & VIR \\
\hline & b4 & $\mathrm{k}-240$ & Azerbaijan & VIR \\
\hline & b5 & $\mathrm{k}-304$ & Azerbaijan & VIR \\
\hline & b6 & $\mathrm{k}-285$ & Azerbaijan & VIR \\
\hline & b7 & $\mathrm{k}-1883^{1,2}$ & Israel & VIR \\
\hline & b8 & $\mathrm{k}-5^{2}$ & Iran & VIR \\
\hline & b9 & $\mathrm{k}-14276^{2}$ & Unknown & VIR \\
\hline & b10 & $\mathrm{k}-280^{2}$ & Spain, Canary Island & VIR \\
\hline & b11 & $\mathrm{k}-1745^{2}$ & Spain, Canary Island & VIR \\
\hline & b12 & $\mathrm{k}-196^{2}$ & Azerbaijan & VIR \\
\hline & b13 & $\mathrm{k}-6^{2}$ & France & VIR \\
\hline & b14 & $\mathrm{k}-157^{2}$ & Tunisia & VIR \\
\hline & - & $\mathrm{k}-217^{3}$ & Azerbaijan & VIR \\
\hline & - & $\mathrm{k}-276^{3}$ & Azerbaijan & VIR \\
\hline & - & $k-306^{3}$ & Azerbaijan & VIR \\
\hline & - & $\mathrm{k}-381^{3}$ & Turkmenistan & VIR \\
\hline \multirow{8}{*}{ A. vaviloviana $(\mathrm{AB})$} & v1 & $\mathrm{k}-1578^{1}$ & Israel & VIR \\
\hline & v2 & $\mathrm{k}-10$ & Ethiopia & VIR \\
\hline & v3 & $\mathrm{k}-782$ & Ethiopia & VIR \\
\hline & $\mathrm{v} 4$ & $\mathrm{k}-755$ & Ethiopia & VIR \\
\hline & v5 & $\mathrm{k}-785$ & Ethiopia & VIR \\
\hline & v6 & $\mathrm{k}-4^{2}$ & unknown & VIR \\
\hline & v7 & $\mathrm{k}-672^{2}$ & Ethiopia & VIR \\
\hline & - & $\mathrm{k}-1738^{3}$ & Ethiopia & VIR \\
\hline \multirow{5}{*}{ A. agadiriana $\left(\mathrm{A}^{\prime} \mathrm{B}^{\prime}\right)$} & ag1 & k-2074 & Morocco & VIR \\
\hline & ag2 & CN-25868 & Morocco & PGRC \\
\hline & ag3 & $\mathrm{CN}-25824^{2}$ & Morocco & PGRC \\
\hline & - & $\mathrm{CN}-25852^{3}$ & Morocco & PGRC \\
\hline & - & $\mathrm{CN}-25837^{1,3}$ & Morocco & PGRC \\
\hline A. magna (AC) & $\mathrm{mg}$ & k-1786 & Morocco & VIR \\
\hline
\end{tabular}


Table 1: Continued.

\begin{tabular}{|c|c|c|c|c|}
\hline Species (genome formula) & Designation in RAPD (Figures 4-6) & Catalogue \# & Country of origin & Source \\
\hline A. murphyi(AC) & $\mathrm{mr}$ & k-1986 & Spain & VIR \\
\hline A. insularis (AC) & is & $\mathrm{k}-2067$ & Italy & VIR \\
\hline A. byzantina (ACD) & $\mathrm{bz}$ & $\mathrm{k}-13351^{2}$ & Spain & VIR \\
\hline
\end{tabular}

${ }^{1}$ Accessions studied by FISH; ${ }^{2}$ not analyzed by C-banding; ${ }^{3}$ not included in RAPD analysis.

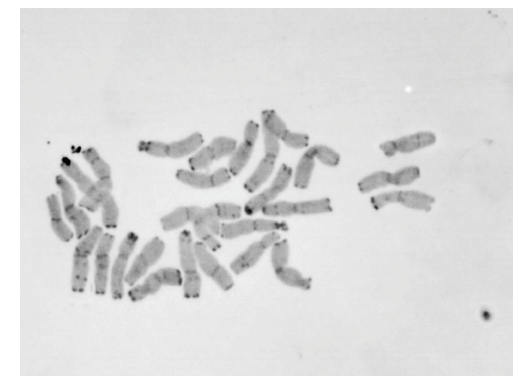

(a)

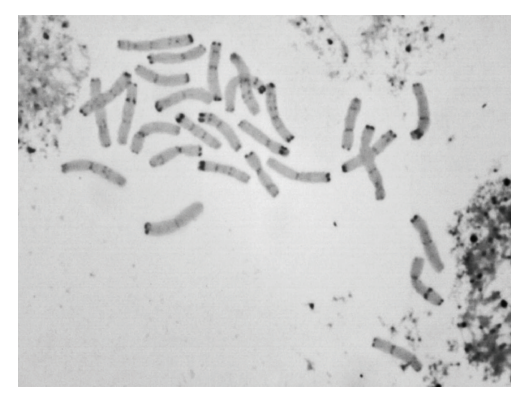

(c)

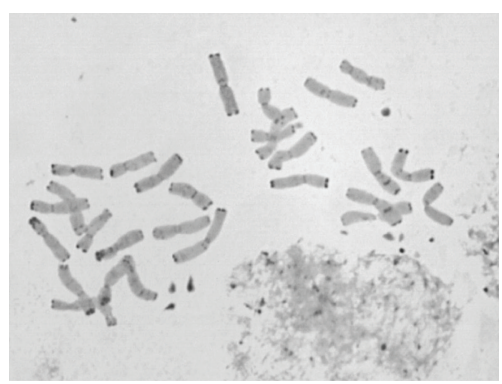

(b)

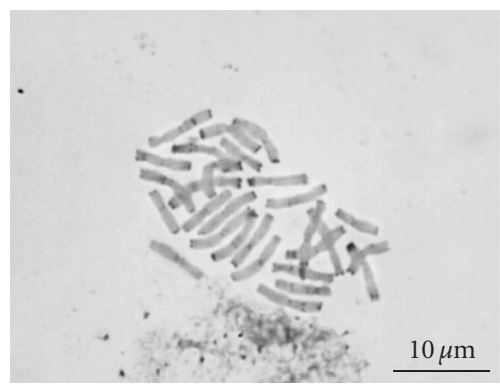

(d)

Figure 1: C-banded metaphase plates of A. barbata, k-276 (a); A. abyssinica, k-4972 (b); A. agadiriana, k-2074 (c) A. vaviloviana, k-875 (d). Scalebar, $10 \mu \mathrm{M}$.

Chromosome $1 A$ had two distinct telomeric and a small intercalary C-band in the proximal region and a weak $\mathrm{C}$ band near the telomere of the long arm. The latter Cband was unusually large in A. barbata, accession k-1920, which also lacked a telomeric C-band in the short arm (Figure 3(c)). Chromosome 2A carried large satellite (one third of the short arm) and polymorphic C-bands in both telomeres. The size of perinucleolar C-band was smaller in A. barbata compared to other species. A faint C-band in the proximal quarter of the long arm was more distinct in $A$. barbata. Chromosome $3 A$ was submetacentric with a small, heterochromatic satellite. In A. abyssinica and A. vaviloviana, it had a clear C-band in the middle of the short arm, which was either weaker or absent in A. barbata. Two small interstitial C-bands were occasionally observed in the long arm. Chromosome $4 A$ possessed relatively large telomeric Cbands in both arms. Small, though clear, intercalary C-bands in the proximal third of the short arm and subtelomeric region of the long arm were the markers of this chromosome. Chromosome $5 A$ had large telomeric blocks and a C-band in the proximal quarter of the long arm. Chromosome $6 \mathrm{~A}$ was submetacentric with distinct C-band in the telomere of the short arm, whereas the adjacent subtelomeric C-band was much weaker. A small C-block in the telomere of the long arm was often seen in $A$. barbata, while it was missing in the two other species. Chromosome $7 A$ was most asymmetric and had a series of characteristic intercalary C-bands in the distal third of the long arm. In morphology and Cbanding pattern, this chromosome was similar to the 7As chromosome of A. strigosa.

Seven chromosome pairs in A. abyssinica, A. barbata, and $A$. vaviloviana attributed to the B-genome differed from the A-genome chromosomes in morphology and Cbanding patterns. Chromosome $8 B$ in $A$. abyssinica and $A$. barbata contained polymorphic telomeric C-bands and a characteristic C-band with variable size in the proximal quarter of the short arm. Chromosome $9 B$ had a weak Cband in the distal third of the short arm, presumably corresponding to the perinucleolar heterochromatin, and this chromosome is apparently related to the chromosome $2 \mathrm{~A}$. A weak telomeric block was sometimes observed in the long arm of chromosome 9B. Chromosome $10 \mathrm{~B}$ with a satellite in the short arm is similar to the SAT-chromosome 3A; in contrast to the latter it possessed a clear, often duplicated $\mathrm{C}$-band in the telomeric region of the long arm. Chromosome $11 \mathrm{~B}$ showed most polymorphic C-banding patterns. 


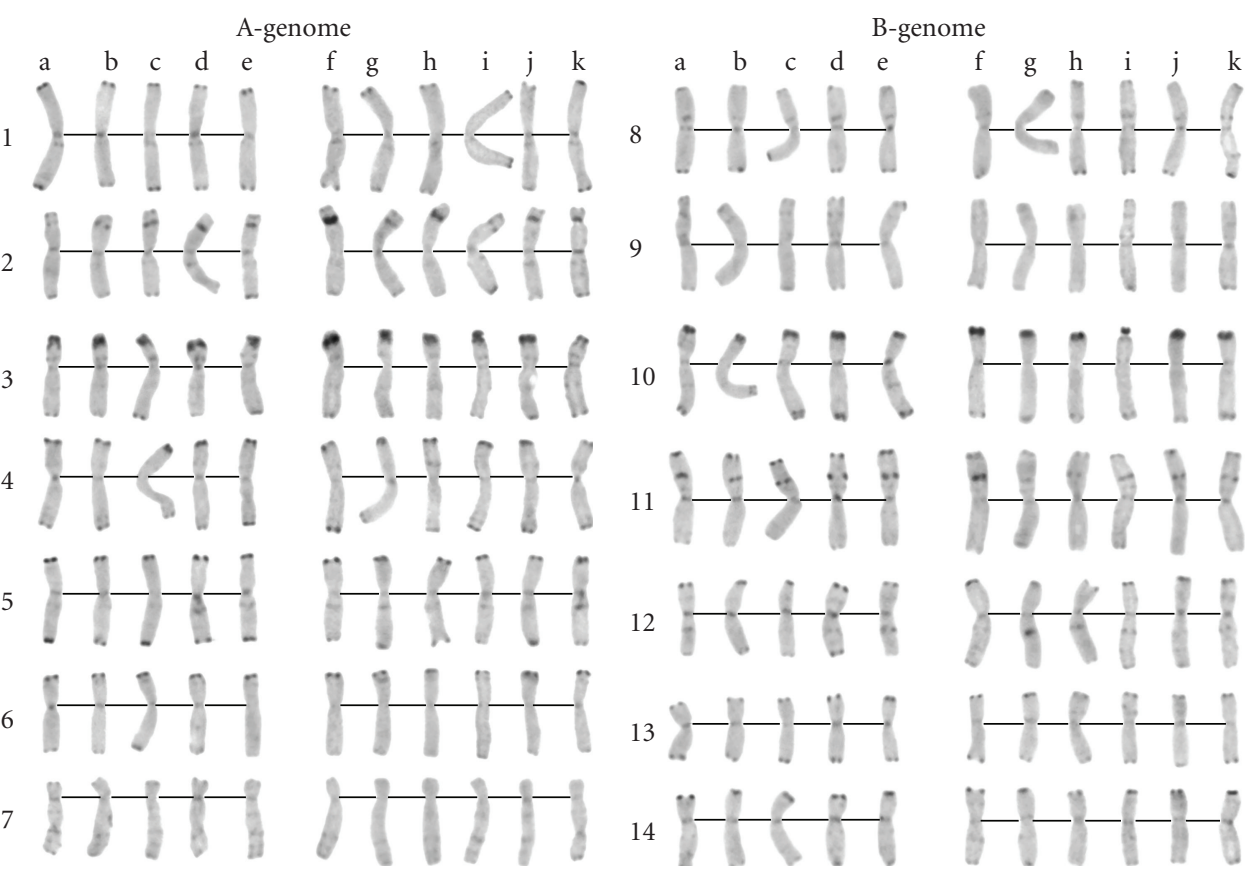

(a)

(b)

Figure 2: Polymorphism of the C-banding patterns in A. abyssinica (a-e) and A. vaviloviana (f-k): a - k-4972, b - k-4978, c - k-5107, d $\mathrm{k}-14819$, e - k-14826, f-k-1578, g-k-10, h-k-782, i - k-755, j-k-785, k-k-1738.

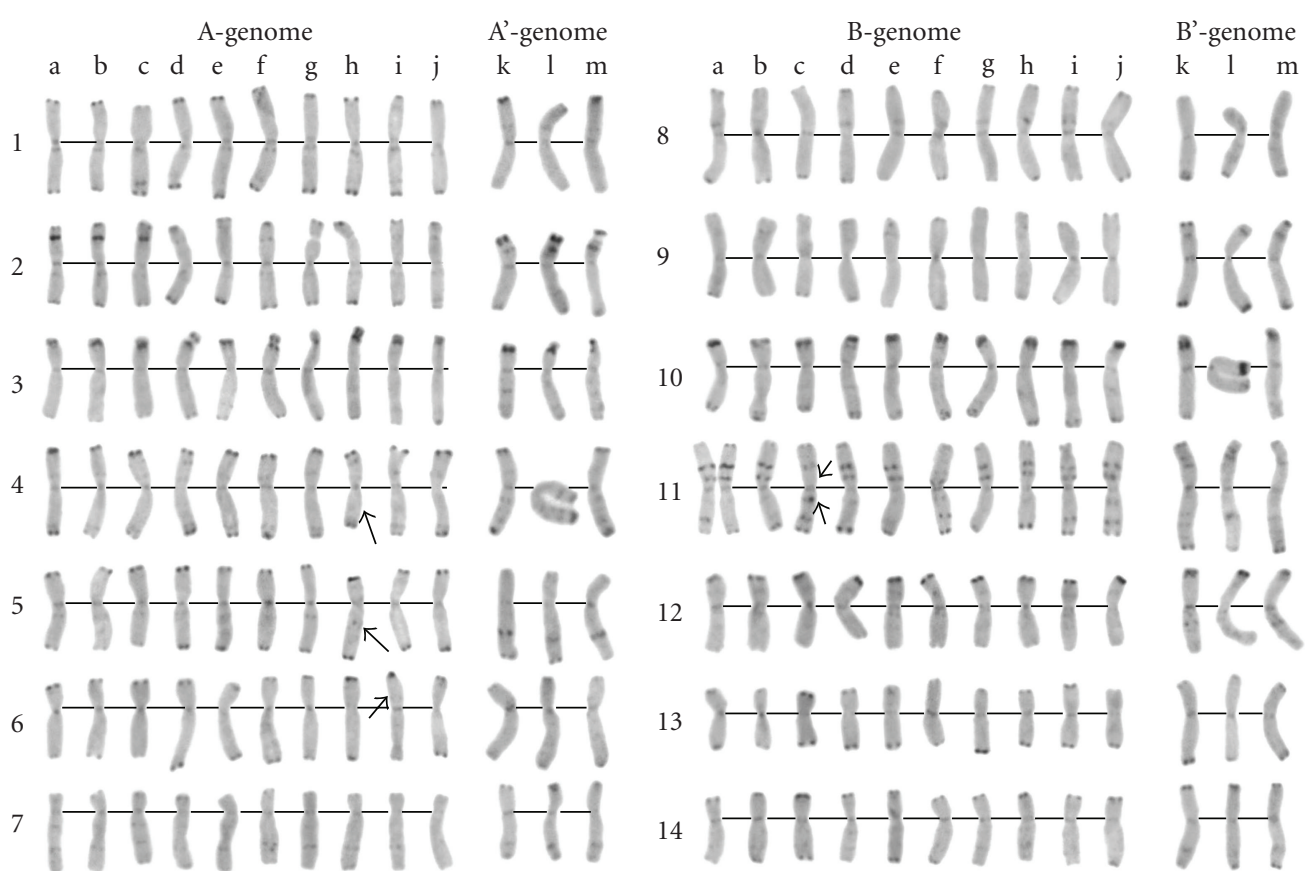

(a)

(b)

Figure 3: Polymorphism of the C-banding patterns in A. barbata (a-j) and A. agadiriana (k-m): a - k-217, b - k-316, c - k-1920, d $\mathrm{k}-230, \mathrm{e}-\mathrm{k}-240, \mathrm{f}-\mathrm{k}-276, \mathrm{~g}-\mathrm{k}-304, \mathrm{~h}-\mathrm{k}-381, \mathrm{i}-\mathrm{k}-285, \mathrm{j}-\mathrm{k}-306, \mathrm{k}-\mathrm{k}-2074, \mathrm{l}-\mathrm{CN}-25868, \mathrm{~m}-\mathrm{CN}-25852$. Chromosomes involved in chromosomal rearrangements are arrowed. 


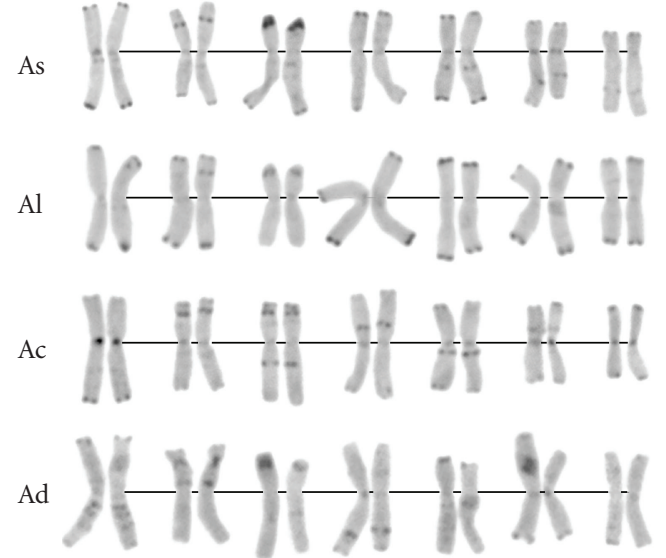

Figure 4: C-banding patterns of karyotypes of diploid Avena species with different variants of the A-genome: As - A. strigosa (k5422), Al - A. longiglumis (k-1874), Ac - A. canariensis (k-293), Ad - A. damascena CN19459.

The distinguishing C-bands were located approximately in the middle (a larger one) and in the proximal quarter (a smaller one) of the short arm. Telomeric C-band of the short arm varied in size from medium (A. abyssinica) to small (A. barbata and A. vaviloviana). In A. abyssinica and $A$. vaviloviana, chromosome $11 \mathrm{~B}$ lacked C-bands in the long arm, however, the majority of $A$. barbata and one $A$. vaviloviana (k-755 Figure 2(i)) accessions carried intercalary blocks in the distal and proximal thirds and in the telomere of the long arm. Chromosome 13B had clear telomeric bands and weak C-bands in the proximal third of the short arm.

The three studied species differed in morphology and C-banding patterns of chromosomes $12 \mathrm{~B}$ and 14B. The chromosome 12B of A. barbata had large telomeric block, a small C-band in the middle of the short arm, and two very weak C-bands in the proximal half of the long arm (Figure 3). Chromosome 12B of A. abyssinica was small and submetacentric; marker interstitial C-bands were located in both arms at approximately equal distances from the centromere. Both telomeric C-bands were polymorphic in size. The Chromosome 12B of A. vaviloviana was similar to the corresponding chromosome of A. abyssinica in terms of location of intercalary bands, but differed from it by the larger size of the long arm, the distal third of which had a small intercalary band. Chromosome $14 B$ of A. abyssinica and $A$. barbata was submetacentric with two marker Cbands, which divided the long arm into three approximately equal part, and distinct telomeric blocks in the short, more rarely in the long arm. The $14 \mathrm{~B}$ chromosome of $A$. vaviloviana was shorter and showed no C-bands in the distal region of the long arm. It may be supposed that a minor translocation had taken place in A. vaviloviana leading to changes in morphology and banding patterns of $12 \mathrm{~B}$ and $14 \mathrm{~B}$ chromosomes.

Avena abyssinica and A. vaviloviana accessions showed only little variation of the C-banding patterns; these species differed in the presence of weak intercalary band in the middle of the long arm of the chromosome 10B and in the morphology and the C-bands distribution on chromosomes $12 \mathrm{~B}$ and $14 \mathrm{~B}$ (Figure 2). Avena barbata was characterized by higher diversity of the C-banding patterns; the accessions differed in the presence/absence of some telomeric and interstitial bands and by the size of certain C-bands. Changed morphologies of the chromosomes $4 \mathrm{~A}$ and $5 \mathrm{~A}$ (accession k-381 from Turkmenistan) can be caused by reciprocal translocation (Figure $3(\mathrm{~h})$ ), whereas positioning of large proximal heterochromatin band to the long arm of the chromosome 11B (accession k-1920, Israel) could be the consequence of pericentric inversion.

Avena agadiriana significantly differed from other ABgenome tetraploids in karyotype structure and C-banding patterns (Figures $1,3(\mathrm{k})-3(\mathrm{~m})$ ). It had the highest heterochromatin content; small and medium-sized C-bands were located in the interstitial and telomeric chromosome regions. A. agadiriana lacked the marker acrocentric chromosome that was characteristic of the $\mathrm{AB}$-genome species, and it also differed from them in morphology of the SAT chromosomes. Due to significant divergence of $A$. agadiriana from three other species of the $\mathrm{AB}$-genome group, the symbol $\mathrm{A}^{\prime} \mathrm{B}^{\prime}$ was used for genome designation.

Chromosome $1 A^{\prime}$ had a prominent telomeric and medium-sized interstitial C-band in the proximal quarter of the short arm. Very weak bands were observed approximately in the middle of the long arm and in the subtelomeric region of the short one. Chromosome $2 A^{\prime}$ carried a satellite with a small nonstained distal part. A small telomeric and a weaker subterminal C-band were observed in the long arm. The distal region of Chromosome $2 \mathrm{~A}^{\prime}$ contained diffuse heterochromatin. Chromosome $3 A^{\prime}$ carried a small, completely heterochromatic satellite in the short arm. The long arm had two or three interstitial bands. Notably, the accessions showed polymorphism in the presence/absence or staining intensity of the proximal block. Chromosome $4 A^{\prime}$ was characterized by a series of four to five clear interstitial bands in the long arm and a small band in the middle or distal region of the short arm. Both telomeres contained clear C-block. Chromosome $5 A^{\prime}$ possessed a large C-band approximately in the middle and a telomeric band of variable size in the long arm. Sometimes, a very weak C-band could be found between them. A telomeric block in the short arm was either absent, or very small. Chromosome $6 A^{\prime}$ was the most asymmetric. Weak, sometimes duplicated C-bands were found in the pericentromeric region of the short arm and in the middle of the long arm. The distal part of the long arm contained diffuse heterochromatin and one-two sharp terminal blocks. $7 \mathrm{~A}^{\prime}$ is one of the smallest chromosomes of $A$. agadiriana. The telomeric block in the short arm was usually bigger than that in the long arm. The marker C-band was located in the distal region of the long arm.

Chromosome $8 B^{\prime}$ is either a medium-sized meta- (k-2074 and CN25852) or submetacentric chromosome (CN25868). It contained a large, sometimes duplicated telomeric block, and a very weak band in the distal region of the long arm. A small C-band was sometimes observed in the proximal part of the short arm. Chromosome $9 B^{\prime}$ was characterized by a large telomeric block in the long and a smaller telomeric 
block in the short arm. The distal quarter of the short arm contained a perinucleolar C-band of approximately the same size as the telomeric block. Only one accession, CN25868, formed a clear secondary constriction on chromosome 9B'. In this case, the perinucleolar heterochromatin was absent, while a distinct $\mathrm{C}$-band was observed in the middle of the satellite. $10 \mathrm{~B}^{\prime}$ is the third SAT chromosome of A. agadiriana. The secondary constriction was either weakly expressed, or was not visible at all. The satellite was narrow and completely heterochromatic. A large marker interstitial C-band was located in the proximal third of the short arm. The long arm of chromosome $10 \mathrm{~B}^{\prime}$ contained a clear telomeric block. The largest chromosome of $A$. agadiriana-11B', showed highly polymorphic C-banding patterns. Ttelomeric C-band was larger in the long arm than in the short one. One to three polymorphic intercalary bands were found in the middledistal region of the long arm. The short arm showed three bands located in the distal region, but several accessions had only one or two of these. Chromosome $12 B^{\prime}$ carried a large, sometimes duplicated telomeric block in the short arm. A distinct proximal band and weaker bands in the middle and the telomeric region were observed in the long arm. Chromosome $13 B^{\prime}$ had clear telomeric blocks in both arms and a small band in the proximal region of the short arm. Chromosome $14 B^{\prime}$ possessed distinct telomeric blocks and a small interstitial band in the distal part of the long arm. Chromosome $14 B^{\prime}$ was very similar to $7 \mathrm{~A}^{\prime}$ in the distribution of C-bands, but differed from it in arm ratio.

3.1. In Situ Hybridization with the $5 S$ and $45 S$ rRNA Gene Probes. Hybridization of the pTa794 and pTa71 DNA probes on mitotic chromosomes of A. barbata, A. abyssinica, A. vaviloviana, and $A$. agadiriana revealed eight $5 \mathrm{~S}$ rDNA signals located on two chromosome pairs, in their short (5S rDNA1 and $5 S$ rDNA1') and long (5S rDNA2 and 5S $r D N A 2^{\prime}$ ) arms (Figures 5(a)-5(d)). These chromosomes also carried major rDNA loci (45S rDNA1 and 45S rDNA1'). Four other major NORs ( $45 S$ rDNA2 and $45 S$ rDNA2') were found on two other chromosome pairs, two of them-45S $r D N A 2^{\prime}$, being the smallest. A. agadiriana differed from other species in having additional minor pTa71 sites (45S rDNA3) in the proximal third of the long arm of a pair of large submetacentric chromosomes (Figure 5(d)).

Four clear signals of $5 \mathrm{~S}$ rDNA probe located in the short (5S rDNA1) and the long (5S rDNA2) arms of a pair of large submetacentric chromosomes were detected in all diploid Avena species having different types of the Agenome: A. strigosa and A. wiestii (As), A. damascena (Ad), A. prostrata (Ap), A. canariensis (Ac), and A. longiglumis (Al) (Figures $4(e)-4(j)$ ). Four major NORs were observed; two of these were located on chromosomes bearing $5 \mathrm{~S}$ rDNA loci (45S rDNA1), and the other two on a pair of metacentric chromosomes (45S rDNA2). Two small signals of the pTa71 probe, corresponding to minor NORs (45S rDNA3) were found on a pair of A. damascena chromosomes (Figure 5(e)).

3.2. RAPD Analysis. Amplification of DNA from 45 accessions of 20 diploid and polyploid oat species using nine primers yielded 698 RAPD fragments, of which only two were monomorphic. The results of analysis were used to calculate genetic distances, create PCO plots (Figures 6 and 7) and generate a dendrogram (Figure 8).

The PCO analysis subdivided all accessions into five groups: one containing the C-genome diploid species, one containing the A-genome diploids, and three groups included different polyploid species. The tetraploid and hexaploid oat species containing the C-genome (tetraploid A. insularis, A. magna and A. murphyi with AC(DC)genomes and hexaploid A. byzantina with ACD-genomes) were grouped together (Figure 6). Accessions of the ABgenome tetraploids formed two well separated groups. Representatives of the closely related $\mathrm{AB}$-genome species $(A$. barbata, A. vaviloviana, A. abyssinica) formed an individual compact group, which was closer to a group of the Agenome diploids, with the As-genome species A. strigosa, A. atlantica, $A$. wiestii, and $A$. hirtula being the closest. The second group included all three accessions of $A$. agadiriana. It was noticeably isolated from the A. barbata/A. vaviloviana/A. abyssinica group and was plotted between the group of the Agenome diploids and a group formed by polyploid species containing $\mathrm{C}$-genome closer to the latter group. It should be noted that both groups of $\mathrm{AB}$-genome species, especially the one that included A. barbata, A. vaviloviana, and A. abyssinica, were noticeably separated from the group of the $\mathrm{C}$-genome diploids.

The relationships of A. barbata, A. vaviloviana, and $A$. abyssinica were studied in more detail using PCO analysis of individual accessions of these three species. The plot shows that they fall into three individual groups, although all of them are close to each other (Figure 7). Notably, the dispersion of the A. barbata accessions was higher than that of the A. vaviloviana and A. abyssinica accessions. Cluster analysis led to similar results (Figure 8). A separate group formed by the $\mathrm{C}$-genome diploids was the most distant from other groups in the dendrogram (100\% bootstrap). A separate clade was formed by A. insularis, A. magna, A. murphyi (AC(DC)-genome), and A. byzantina (ACD-genome). The group of $A$. agadiriana accessions was clearly separated from the others. It was attributed to a large polymorphic cluster with $72 \%$ bootstrap support, which also included all Agenome diploids and the AB-genome tetraploids (A. barbata, A. vaviloviana and $A$. abyssinica). Interestingly, the three $A$. agadiriana accessions differed significantly from each other with accession CN25824 being the most isolated from other two. Differences between them were comparable with those between individual diploid species with the As-genome, and were appreciably larger than differences between $A$. barbata, A. vaviloviana, and $A$. abyssinica.

Besides $A$. agadiriana, the same large cluster included a subcluster of A. barbata, A. vaviloviana, and A. abyssinica, the related subcluster of the As-genome diploids as well as of diploid species with other A-genome types. Each of them formed well-separated branches in the dendrogram. Within the subcluster of A. barbata, A. vaviloviana, and A. abyssinica, accessions of each species formed a separate group, with one exception. The groups of $A$. vaviloviana and $A$. abyssinica accessions were closer to each other than to the group of $A$. barbata accessions. It should be stressed 


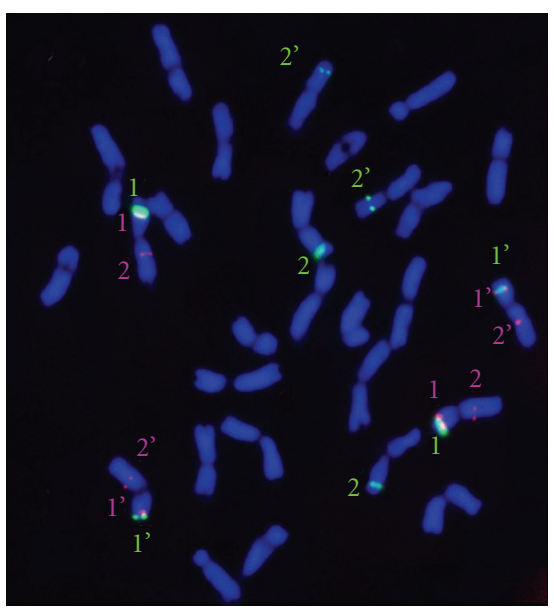

(a)

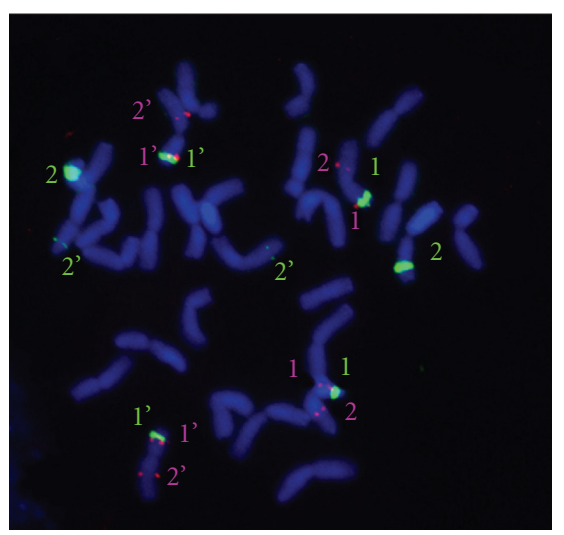

(c)

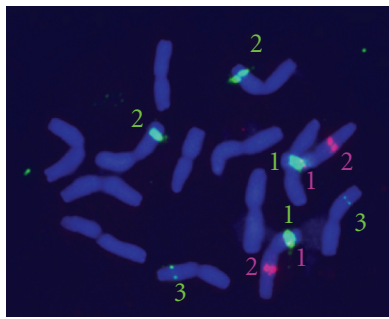

(e)

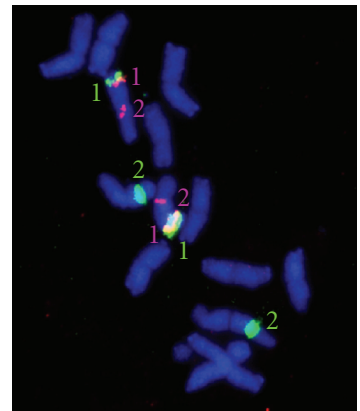

(h)

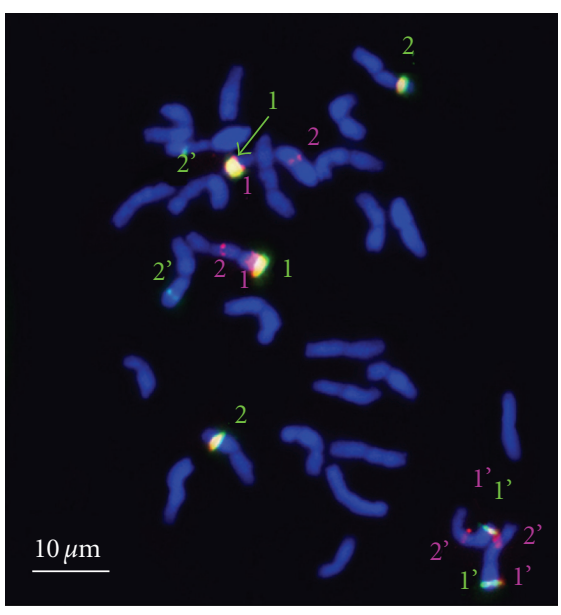

(b)

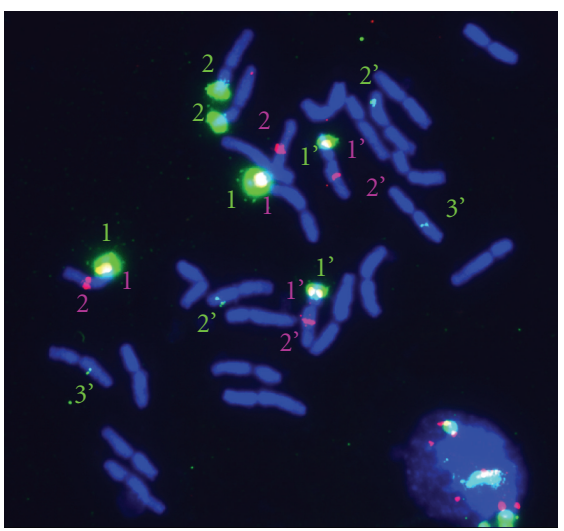

(d)

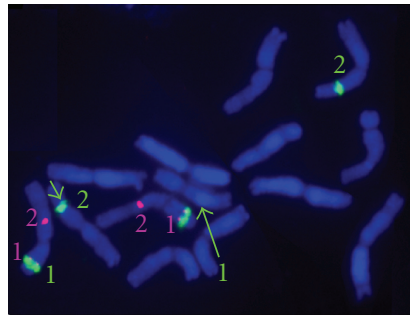

(f)

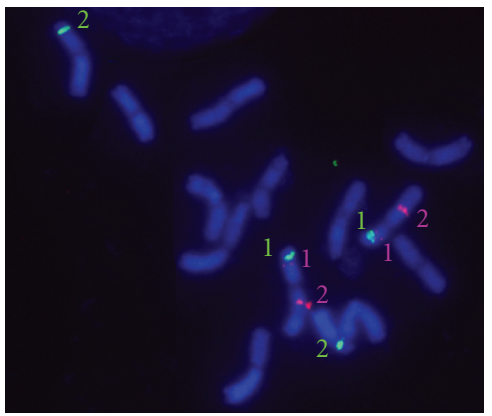

(i)

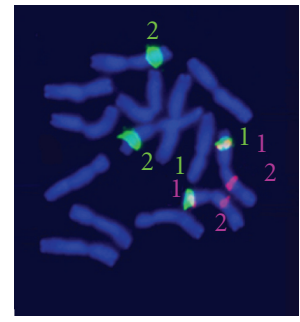

(g)

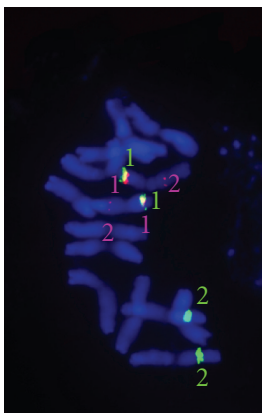

(j)

FIgURE 5: FISH with pTa71 (green signals) and pTa794 (red signals) DNA probes on chromosomes of A. abyssinica, k-4972 (a); A. vaviloviana, k-1578 (b); A. barbata, k-1883 (c); A. agadiriana, CN 25837 (d); A. damascena, CN19459 (e); A. strigosa, k-4485 (f); A. wiestii, k-94 (g); A. prostrata, k-2055 (h); A. canariensis, k-293 (i); A. longiglumis, k-1810 (j). The 5S rDNA loci are designated with red numerals and $45 \mathrm{~S}$ rDNA loci with green numerals. The numerals correspond to the number of the respective loci in the text (i.e., green "1" is $45 \mathrm{~S}$ rDNA1, etc.) 


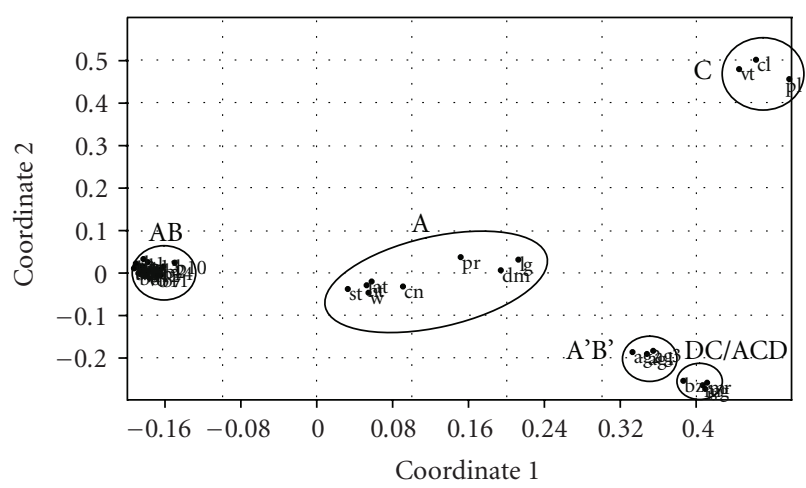

FIgURE 6: Relationships of Avena species with different genomes, as revealed by a principal coordinate analysis of RAPD data. Designations of accessions are given in Table 1.

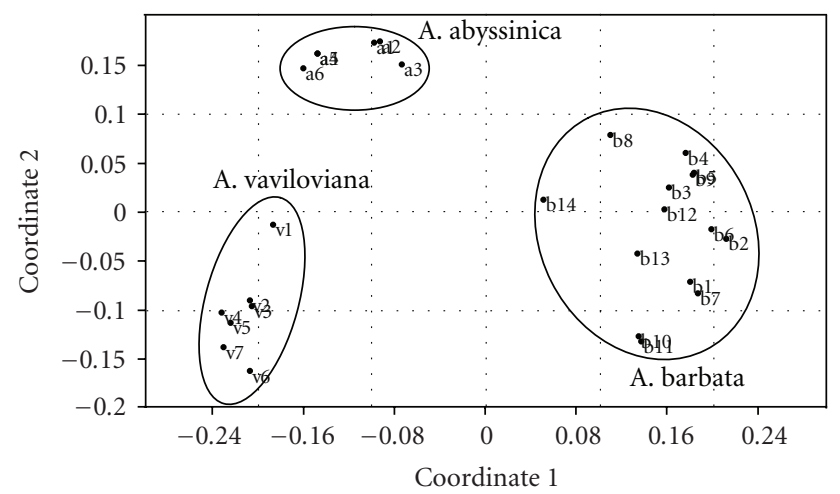

Figure 7: Relationships of A. barbata, A. abyssinica, and $A$. vaviloviana according to PCO analysis of RAPD data.

that clustering of $A$. barbata accessions in a separate group had no bootstrap support, and that the A. barbata accession $\mathrm{k}-280$ formed an individual branch within this subcluster. Therefore, according to the results of cluster analysis, $A$. vaviloviana and $A$. abyssinica are not well-separated species and fall within the $A$. barbata variation range.

\section{Discussion}

The phylogeny of the genus Avena has been studied for over 80 years, and still many questions related to the origin of species and the mechanisms of inter- and intraspecific divergence remain to be answered. Among these is the clarification of phylogenetic relationships between tetraploid species within the $\mathrm{AB}$-genome group that includes $A$. barbata, A. vaviloviana, A. abyssinica, and A. agadiriana. Such questions can be successfully addressed using chromosome technologies (C-banding and in situ hybridization), as well as molecular approaches, including RAPD, RFLP, and AFLPanalyses [16, 17, 29-32].

Examination of a broad range of cereal species demonstrated that the relative position of the $5 \mathrm{~S}$ and $45 \mathrm{~S}$ rRNA loci is a highly conservative characteristic of genomes $[33,34]$ and therefore, these markers can be used for determination of the origin of species or genomes. In agreement with previous observations $[8,12]$, distribution of major NORs and $5 \mathrm{~S}$ rDNA loci on chromosomes of four tetraploid oat species was similar. They all possessed a "duplicated number" of similarly located $5 \mathrm{~S}$ and $45 \mathrm{~S}$ rRNA loci, indicating a close relationship between the $\mathrm{A}$ and $\mathrm{B}$ genomes. In turn, hybridization patterns of each of these genomes were similar to those of $A$. strigosa $[8,35-37]$ and other A-genome diploids (Figures 3(e)-3(g)) thus supporting the hypothesis that they both derived from the A-genome progenitors species. This was further confirmed by the RAPD analysis.

Other results show that $A$. agadiriana belongs to the same genomic group as $A$. barbata, $A$. vaviloviana and A. abyssinica. However, in contrast to these species, all $A$. agadiriana accessions described previously [38] and those studied here carried an additional minor $45 \mathrm{~S}$ rDNA locus. This assumes that $A$. agadiriana must have originated from another diploid progenitor. It is noteworthy that among all A-genome diploids only $A$. damascena contained a minor NOR (Figure 5(e)). Although the relative position of minor rDNA sites on the chromosomes of $A$. agadiriana and $A$. damascena was somewhat different (Figures 5(d) and 5(e)), this diploid species may be regarded as one of the possible ancestors of the polyploid.

The results of RAPD analysis confirmed the significant divergence within the species of AB-genome group (Figures 6-8). In the scatter plot, they formed two appreciably distinct groups. The first one included three related species $A$. abyssinica, A. barbata, and A. vaviloviana and it was the closest to the group of the A-genome diploids, especially Asgenome species. Accessions of A. abyssinica, A. barbata, and A. vaviloviana formed a very dense group in the scatter plot, thus making their comparison very difficult (Figure 6). Also in the UPGMA dendrogram A. vaviloviana and A. abyssinica do not appear as well-isolated species, but form a separate, bootstrap-supported group within the A. barbata subcluster. To clarify their relationship, the PCO analysis was performed specifically for these three species (Figure 7). Although their RAPD spectra differed in few minor fragments only, accessions of each of these species were spatially separated in the scatter plot. A wider group was formed by A. barbata, while $A$. vaviloviana and $A$. abyssinica formed two adjacent compact groups. This agrees well with their geographical distribution: A. abyssinica and A. vaviloviana are endemic to Ethiopia, Yemen, and Eritrea and grow within limited areas, whereas the distribution area of A. barbata is considerably broader $[39,40]$.

Close relationships between $A$. abysinica, A. barbata, and A. vaviloviana were first revealed using conventional chromosome staining $[1,5]$. With the C-banding we discovered slight, but reproducible differences between $A$. abyssinica, A. barbata, and A. vaviloviana karyotypes, which agrees with previous observations [11]. With the help of in situ hybridization with the A-genome-specific DNA probe an intergenomic translocation was found in A. vaviloviana, but it was absent in A. barbata [12]. Multivalent chromosome associations observed in meiotic cells of $A$. barbata $\mathrm{x} A$. vaviloviana hybrids [3] are indications of possible minor translocations. Our results suggest $A$. vaviloviana differs from 


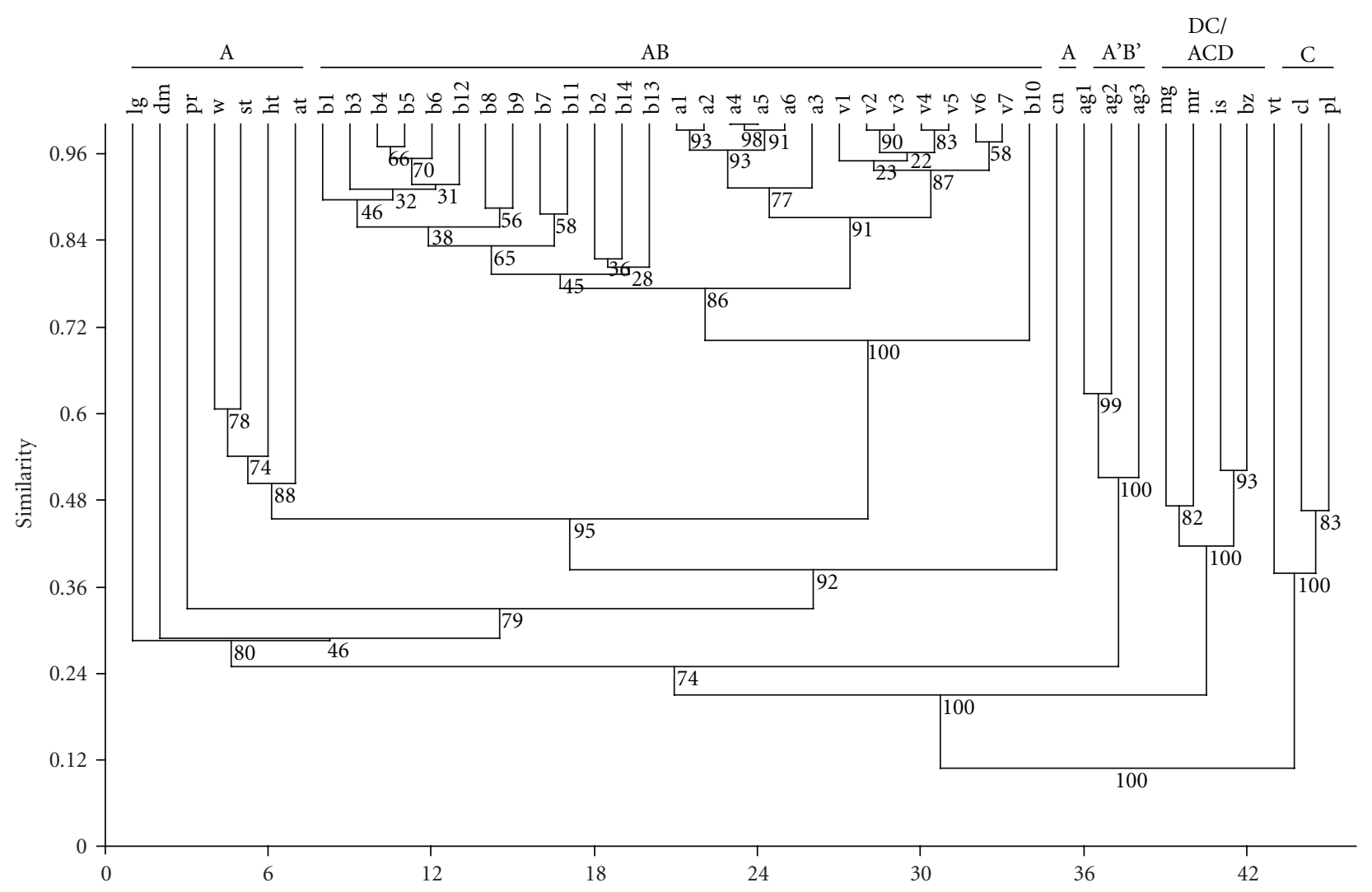

FIGURE 8: UPGMA tree of Jaccard distances based on RAPD data describing the genetic relationships of Avena species with different genome types. Bootstrap values are shown on the nodes. Designations of accessions are the same as in Table 1.

two other species by minor translocation involving chromosomes 12B and 14B. Nevertheless, this rearrangement has not led to the creation of effective isolation mechanisms between species capable of hybridizing and producing fertile progeny [7].

Our results showed that the divergence of three ABgenome tetraploids was accompanied by minor changes in the heterochromatin distribution. A. barbata had more variable C-banding patterns, which can be due to the wider area of this species. RAPD analysis also revealed higher intraspecific diversity of $A$. barbata. Thus, RAPD spectra within the accessions of $A$. abyssinica and $A$. vaviloviana were similar; these species differed from each other and from A. barbata only in the presence or absence of few minor fragments. A. barbata appeared to be more polymorphic; some accessions of this species contain RAPD-fragments characteristic of either A. abyssinica, or A. vaviloviana. In addition, the fragments amplified with primers 9A, 1D, and $13 \mathrm{~N}$ were identical in all three species. These results strongly suggest that these three tetraploid species originated from one common ancestor, and it is hardly possible that A. barbata is genetically distinct from A. abyssinica and A. vaviloviana and has different genome constitution, as was hypothesized by [32]. It can also be assumed that the "founder effect" played an important role in the evolution of A. abyssinica and A. vaviloviana.
Our study confirms that a diploid species from the Asgenome group was the A-genome donor to A. abyssinica, $A$. barbata, and A. vaviloviana. This is supported by the results of meiotic analysis of A. barbata $\times$ A. strigosa hybrids $[1,5]$, by similarity of their chromosomes [7], and by molecular data $[16,29]$. The origin of the second genome of these species has not been determined.

The autotetraploid origin of the $\mathrm{AB}$-genome species is questionable since they contained only three pairs of satellite chromosomes instead of the expected four [41]. In addition, analysis of meiotic chromosome pairing in the A. barbata $\mathrm{x} A$. strigosa $(4 \mathrm{x})$ hybrids contradicted this hypothesis [42]. Morphology and C-banding patterns of the $\mathrm{B}$-genome chromosomes differed significantly from that of the A-genome chromosomes. We also failed to find complete correspondence of amplification spectra of the A. abyssinica, A. barbata, and A. vaviloviana with the spectra of any of the A-genome diploid species. This may indicate that they have originated as the result of hybridization of different diploid species of the A-genome group, and the newly formed tetraploid further hybridized with the unknown A-genome diploid.

The results of Irigoyen et al. [12] favored the hypothesis of allopolyploid origin of the AB-genome species. Using in situ hybridization and Southern blotting, they showed that the A-genome-specific sequence As120a from A. strigosa and 
A. longiglumis is present in the A-genome of A. barbata and $A$. vaviloviana, but is absent in the B-genome. The sequence $A s 120 a$ is not found in some A-genome diploid Avena, in particular, in A. canariensis and A. damascena [43]. Hence, one of these species could be the B-genome progenitor. However, karyotypes of both A. canariensis and A. damascena (Figure 4, Ac and Ad) differ considerably from the B-genome chromosomes in morphology and C-band distribution. Therefore, the origin of the B-genome remains an open question.

Our investigation further confirms an isolated position of A. agadiriana. It differs from the AB-genome tetraploids in karyotype structure, higher heterochromatin content and C-bands distribution on chromosomes. According to RAPD analysis, A. agadiriana is noticeably distant from other ABgenome species and in a plot is positioned between the Agenome diploids and the $\mathrm{C}$-genome containing polyploids being closer to the latter.

It should be noted that only one of the studied accessions, namely CN25868, was characterized here for the first time while two other accessions, k-2074 (= CAV6757 = CN25851) and CN25852 (= CAV6758), have been studied previously by Jellen and Gill [44]. Combining of our results allow us to suggest that $A$. agadiriana displays the broadest intraspecific polymorphism. This species is known to fall into two geographic groups-Northern and Southern [38, 45]. Cbanding analysis also revealed two chromosomal types in $A$. agadiriana which differ from each other by five out of fourteen chromosome pairs (2A, 4A, 7A, 9B and 14B). Most accessions belong to chromosomal type 1 , and only twoCAV6729 and CAV6730 studied by [44] can be attributed to chromosomal type 2 .

Chromosomal type 1 was found among the accessions from both Southern and Northern geographic groups of $A$. agadiriana. There were no significant differences between them, except for the functional activity of the NOR on chromosome 9B. By contrast, both accessions with chromosomal type 2 were from the Northern group. In the dendrogram, one of these, CN25824 (= CAV6730), was clearly separated from two $A$. agadiriana accessions belonging to chromosomal type 1 (Figure 8 ). An isolated position of forms with chromosomal type 2 among other accessions of $A$. agadiriana is supported by the results of C-banding, isozyme, and FISH analyses [38, 44, 45]. Presumably, they might have diverged as the result of considerable chromosomal rearrangements leading, in particular, to the loss of nucleolus organizer region. However, the chromosomal aberrations alone cannot explain all of the differences between two chromosomal types. Hybridization with other polyploid oat species, especially of the C-genome group could have played a significant role in the origin of chromosomal type 2 . The possibility of such a scenario is confirmed by the presence of diffuse heterochromatin (characteristic of the C-genome) in some chromosomes of A. agadiriana. RAPD fingerpints of the accession CN25824 (chromosomal type 2) contain fragments that are present in some C-genome polyploids, but are absent in the Agenome diploids and other representatives of the AB-genome group.
Though $A$. agadiriana undoubtedly belongs to the ABgenome group, the donors of its $\mathrm{A}$ and $\mathrm{B}$ genomes are not known. Comparison of chromosomes of this species with diploid Avena carrying different variants of the A-genome (Figure 4) suggests that $A$. damascena could be one of its ancestors. Similarity of some chromosomes of these species in the presence and position of marker C-bands, in the smaller size of satellites on chromosome $2 \mathrm{~A}$ as well as in the presence of a minor NOR support this hypothesis.

RAPD analysis showed equal similarity between $A$. agadiriana and different A-genome diploids. Therefore, $A$. agadiriana might have originated from hybridization of two species with different types of the A-genome, and more than two species could have contributed to its origin. On the other hand, the considerable differences between A. agadiriana and the extant diploid species and high intraspecific diversity suggest that possibly it is one of the most ancient polyploids within the genus Avena. Differentiation of A. agadiriana populations could be promoted by their geographic isolation due to the fact that the distribution area of this species is crossed by the latitudinally stretched mountain ridge.

It is important that all studied species in the AB-genome group displayed common phenomena, namely decrease of $45 \mathrm{~S}$ rDNA sites on the B-genome chromosomes that was especially clear in $A$. barbata and A. agadiriana. Decrease of NORs on chromosomes of one of the genomes of tetraploid $A$. barbata and A. vaviloviana has also been recorded by Irigoyen et al. [12]. Ag-NOR staining showed that some nuclei contain five to six nucleoli, though most cells in A. barbata, A. abysinica and A. vaviloviana form four nucleoli [11]. Therefore, one of the four chromosome pairs carrying the 45S rRNA gene sites (presumably, 9B) lost the nucleoli-forming activity, and in the other chromosome pair (10B) this activity is reduced. The smaller signal size at the respective loci may be due to the partial loss of the rRNA gene copies. Partial elimination of the $45 \mathrm{~S}$ rRNA genes from one of the parental genomes of a polyploid, accompanied by the loss of nucleoli-forming activity (amphiplasty) has been recorded for many plant species and hybrids [46-51], and, presumably, this may be one of the mechanisms of "cytological diploidization" of polyploids.

\section{Acknowledgments}

This paper was supported in part by the Russian State Foundation for Basic Research (Project no. 08-04-00306) and by the Programs from the Presidium of the Russian Academy of Sciences "Biodiversity" and "Dynamics of Gene-Pools of Plants, Human, and Animals.” The authors greatly appreciate Dr. Axel Diederichsen (Plant Gene Resources of Canada) for providing the material for investigation.

\section{References}

[1] T. Rajharthy and J. W. Morrison, "Chromosome morphology in the genus Avena," Canadian Journal of Botany, vol. 37, no. 3, pp. 331-337, 1959. 
[2] M. J. Leggett and G. S. Markland, "The genomic structure of Avena revealed by GISH," in Proceedings of the Kew Chromosome Conference IV, pp. 133-139, 1995.

[3] J. H. W. Holden, "Species relationships in the Avenae," Chromosoma, vol. 20, no. 1, pp. 75-124, 1966.

[4] A. Katsiotis and R. A. Forsberg, "Production and cytogenetics of tetraploid-octoploid Avena hybrids," Plant Breed, vol. 114, no. 2, pp. 137-143, 1995.

[5] R. S. Sadasivaiah and T. Rajharthy, "Genome relationships in tetraploid Avena," Canadian Journal of Genetics and Cytology, vol. 10, no. 3, pp. 655-669, 1968.

[6] G. Ladizinsky and D. Zohary, "Genetic relationships between diploids and tetraploids in series Eubarbatae of Avena," Canadian Journal of Genetics and Cytology, vol. 10, no. 1, pp. 68-81, 1968.

[7] G. T. Rajharthy and H. Thomas, "Cytogenetics of oats (Avena L.)," Llaneous Publications of the Genetics Society of Canada, no. 2, pp. 1-90, 1974.

[8] A. Katsiotis, M. Hagidimitriou, and J. S. Heslop-Harrison, "The close relationship between the A and B genomes in Avena L. (Poaceae) determined by molecular cytogenetic analysis of total genomic, tandemly and dispersed repetitive DNA sequences," Annals of Botany, vol. 79, no. 2, pp. 103-109, 1997.

[9] J. M. Leggett and G. S. Markhand, "The genomic configuration of Avena revealed by GISH," in Proceedings of the Kew Chromosome Conference, vol. 4, pp. 133-139, Kew Royal Botanical Gardens, 1995.

[10] T. Oinuma, "Karyomorphology of cereals," Biological Journal of Okayama University, vol. 1, pp. 12-71, 1952.

[11] A. Fominaya, C. Vega, and E. Ferrer, "C-banding and nucleolar activity of tetraploid Avena species," Genome, vol. 30, no. 5, pp. 633-638, 1988.

[12] M. L. Irigoyen, Y. Loarce, C. Linares, E. Ferrer, M. Leggett, and A. Fominaya, "Discrimination of the closely related A and B genomes in AABB tetraploid species of Avena," Theoretical and Applied Genetics, vol. 103, no. 8, pp. 1160-1166, 2001.

[13] J.M. Leggett, "Interspecific hybrids in Avena," Genome, vol. 32, no. 2, pp. 346-348, 1989.

[14] J. M. Leggett, G. Ladizinsky, P. Hagberg, and M. Obanni, "The distribution of nine Avena species in Spain and Morocco," Canadian Journal of Botany, vol. 70, no. 2, pp. 240-244, 1992.

[15] B. R. Baum and G. Fedak, "A new tetraploid species of Avena discovered in Morocco," Canadian Journal of Botany, vol. 63, no. 8, pp. 1379-1385, 1985.

[16] Y.-B. Fu and D. J. Williams, "AFLP variation in 25 Avena species," Theoretical and Applied Genetics, vol. 117, no. 3, pp. 333-342, 2008.

[17] W.-T. Li, Y.-Y. Peng, Y.-M. Wei, B. R. Baum, and Y.-L. Zheng, "Relationships among Avena species as revealed by consensus chloroplast simple sequence repeat (ccSSR) markers," Genetic Resources and Crop Evolution, vol. 56, no. 4, pp. 465-480, 2009.

[18] S. Fabijanski, G. Fedak, K. Armstrong, and I. Altosaar, "A repeated sequence probe for the C genome in Avena (Oats)," Theoretical and Applied Genetics, vol. 79, no. 1, pp. 1-7, 1990.

[19] H. Thomas, "New species of Avena," in Proceedings of the 3rd International Oat Conference, pp. 18-23, Lund, Sweden, 1989.

[20] K. Edwards, C. Johnstone, and C. Thompson, "A simple and rapid method for the preparation of plant genomic DNA for PCR analysis," Nucleic Acids Research, vol. 19, no. 6, p. 1349, 1991.

[21] D. B. Dorokhov and E. Klocke, "A rapid and economic technique for RAPD analysis of plant genomes," Russian Journal of Genetics, vol. 33, no. 4, pp. 358-365, 1997.
[22] S. V. Goryunova, E. Z. Kochieva, N. N. Chikida, and V. A. Pukhalskyi, "Phylogenetic relationships and intraspecific variation of D-genome Aegilops L. as revealed by RAPD analysis," Russian Journal of Genetics, vol. 40, no. 5, pp. 515523, 2004.

[23] E. Z. Kochieva, S. V. Goryunova, and A. A. Pomortsev, "RAPD analysis of the genome in species of the genus hordeum," Russian Journal of Genetics, vol. 37, no. 8, pp. 905-910, 2001.

[24] E. D. Badaeva, N. S. Badaev, B. S. Gill, and A. A. Filatenko, "Intraspecific karyotype divergence in Triticum araraticum (Poaceae)," Plant Systematics and Evolution, vol. 192, no. 1-2, pp. 117-145, 1994.

[25] W. L. Gerlach and T. A. Dyer, "Sequence organization of the repeated units in the nucleus of wheat which contains 5SrRNA genes," Nucleic Acids Research, vol. 8, no. 21, pp. 48514865, 1980.

[26] W. L. Gerlach and J. R. Bedbrook, "Cloning and characterization of ribosomal RNA genes from wheat and barley," Nucleic Acids Research, vol. 7, no. 7, pp. 1869-1885, 1979.

[27] E. D. Badaeva, B. Friebe, and B. S. Gill, "Genome differentiation in Aegilops. 1. Distribution of highly repetitive DNA sequences on chromosomes of diploid species," Genome, vol. 39, no. 2, pp. 293-306, 1996.

[28] E. D. Badaeva, I. G. Loskutov, O. Yu. Shelukhina, and V. A. Pukhalsky, "Cytogenetic analysis of diploid Avena L. species containing the as genome," Russian Journal of Genetics, vol. 41, no. 12, pp. 1428-1433, 2005.

[29] A. Drossou, A. Katsiotis, J. M. Leggett, M. Loukas, and S. Tsakas, "Genome and species relationships in genus Avena based on RAPD and AFLP molecular markers," Theoretical and Applied Genetics, vol. 109, no. 1, pp. 48-54, 2004.

[30] R. Alicchio, M. Bioni, E. Nocelli, and T. Giovannini, "RFLPand RAPD-based genetic relationships of seven diploid species of Avena with the A genome," Genome, vol. 42, no. 5, pp. 950959, 1999.

[31] R. Alicchio, L. Aranci, and L. Conte, "Restriction fragment length polymorphism based phylogenetic analysis of Avena L," Genome, vol. 38, no. 6, pp. 1279-1284, 1995.

[32] Y.-Y. Peng, Y.-M. Wei, B. R. Baum, and Y.-L. Zheng, "Molecular diversity of the $5 \mathrm{~S}$ rRNA gene and genomic relationships in the genus Avena (Poaceae: Aveneae)," Genome, vol. 51, no. 2, pp. 137-154, 2008.

[33] E. D. Badaeva, B. Friebe, and B. S. Gill, "Genome differentiation in Aegilops. 2. Physical mapping of 5S and 18S-26S ribosomal RNA gene families in diploid species," Genome, vol. 39, no. 6, pp. 1150-1158, 1996.

[34] S. Taketa, H. Ando, K. Takeda, M. Ichii, and R. Von Bothmer, "Ancestry of American polyploid Hordeum species with the I genome inferred from $5 \mathrm{~S}$ and 18S-25S rDNA," Annals of Botany, vol. 96, no. 1, pp. 23-33, 2005.

[35] C. Linares, J. González, E. Ferrer, and A. Fominaya, “The use of double fluorescence in situ hybridization to physically map the positions of $5 \mathrm{~S}$ rDNA genes in relation to the chromosomal location of 18S-5.8S-26S rDNA and a C genome specific DNA sequence in the genus Avena," Genome, vol. 39, no. 3, pp. 535$542,1996$.

[36] O. Yu. Shelukhina, E. D. Badaeva, T. A. Brezhneva, I. G. Loskutov, and V. A. Pukhalsky, "Comparative analysis of diploid species of Avena L. using cytogenetic and biochemical markers: Avena canariensis Baum et Fedak and A. longiglumis Dur," Russian Journal of Genetics, vol. 44, no. 6, pp. 694-701, 2008. 
[37] C. Linares, A. Serna, and A. Fominaya, "Chromosomal organization of a sequence related to LTR-like elements of Ty1copia retrotransposons in Avena species," Genome, vol. 42, no. 4, pp. 706-713, 1999.

[38] M. Hayasaki, T. Morikawa, and J. M. Leggett, "Intraspecific variation of 18S-5.8S-26S rDNA sites revealed by FISH and RFLP in wild oat, Avena agadiriana," Genes and Genetic Systems, vol. 76, no. 1, pp. 9-14, 2001.

[39] O. Yu. Shelukhina, E. D. Badaeva, I. G. Loskutov, and V. A. Pukhal'skiy, "A comparative cytogenetic study of the tetraploid oat species with the A and C genomes: Avena insularis, A. magna , and A. murphyi," Russian Journal of Genetics, vol. 43, no. 6, pp. 613-626, 2007.

[40] B. R. Baum, Oats: Wild and Cultivated. A Monograph of the Genus Avena L. (Poaceae), Thorn Press, Ottawa, Canada, 1977.

[41] G. Ladizinsky, "Genome relationships in the diploid oats," Chromosoma, vol. 47, no. 1, pp. 109-117, 1974.

[42] I. Nishiyama, "Cytogenetical studies in Avena. I. Chromosome associations in hybrids between A. barbata Pott. and autotetraploids A. strigosa Schreb," Cytologia, vol. 7, pp. 276-281, 1936.

[43] C. Linares, E. Ferrer, and A. Fominaya, "Discrimination of the closely related A and D genomes of the hexaploid oat Avena sativa L," Proceedings of the National Academy of Sciences of the United States of America, vol. 95, no. 21, pp. 12450-12455, 1998.

[44] E. N. Jellen and B. S. Gill, "C-banding variation in the Moroccan oat species Avena agadiriana $(2 \mathrm{n}=4 \mathrm{x}=28)$," Theoretical and Applied Genetics, vol. 92, no. 6, pp. 726-732, 1996.

[45] T. Morikawa and J. M. Leggett, "Isozyme polymorphism and genetic differentiation in natural populations of a new tetraploid species Avena agadiriana, from Morocco," Genetic Resources and Crop Evolution, vol. 52, no. 4, pp. 363-370, 2005.

[46] A. B. Shcherban, E. D. Badaeva, A. V. Amosova, I. G. Adonina, and E. A. Salina, "Genetic and epigenetic changes of rDNA in a synthetic allotetraploid, Aegilops sharonensis $\times$ Ae. umbellulata," Genome, vol. 51, no. 4, pp. 261-271, 2008.

[47] P. D. Cluster, O. Calderini, F. Pupilli, F. Crea, F. Damiani, and S. Arcioni, "The fate of ribosomal genes in three interspecific somatic hybrids of Medicago sativa: three different outcomes including the rapid amplification of new spacer-length variants," Theoretical and Applied Genetics, vol. 93, no. 5-6, pp. 801-808, 1996.

[48] O. Pontes, R. J. Lawrence, N. Neves, et al., "Natural variation in nucleolar dominance reveals the relationship between nucleolus organizer chromatin topology and rRNA gene transcription in Arabidopsis," Proceedings of the National Academy of Sciences of the United States of America, vol. 100, no. 20, pp. 11418-11423, 2003.

[49] C. S. Pikaard, "Genomic change and gene silencing in polyploids," Trends in Genetics, vol. 17, no. 12, pp. 675-677, 2001.

[50] N. A. Eckardt, "A sense of self: the role of DNA sequence elimination in allopolyploidization," The Plant Cell, vol. 13, no. 8, pp. 1699-1704, 2001.

[51] N. Nikoloudakis and A. Katsiotis, "The origin of the Cgenome and cytoplasm of Avena polyploids," Theoretical and Applied Genetics, vol. 117, no. 2, pp. 273-281, 2008. 

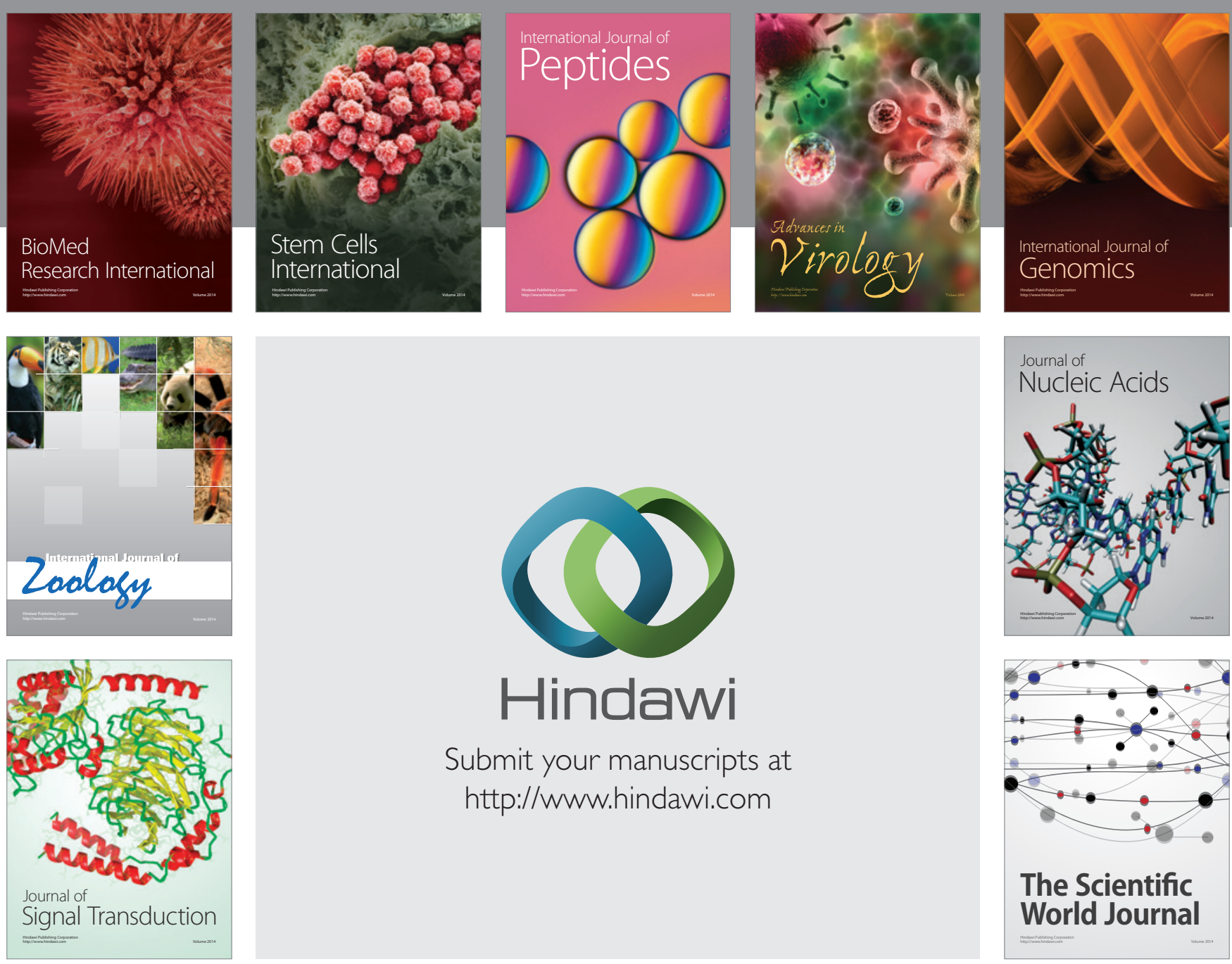

Submit your manuscripts at

http://www.hindawi.com
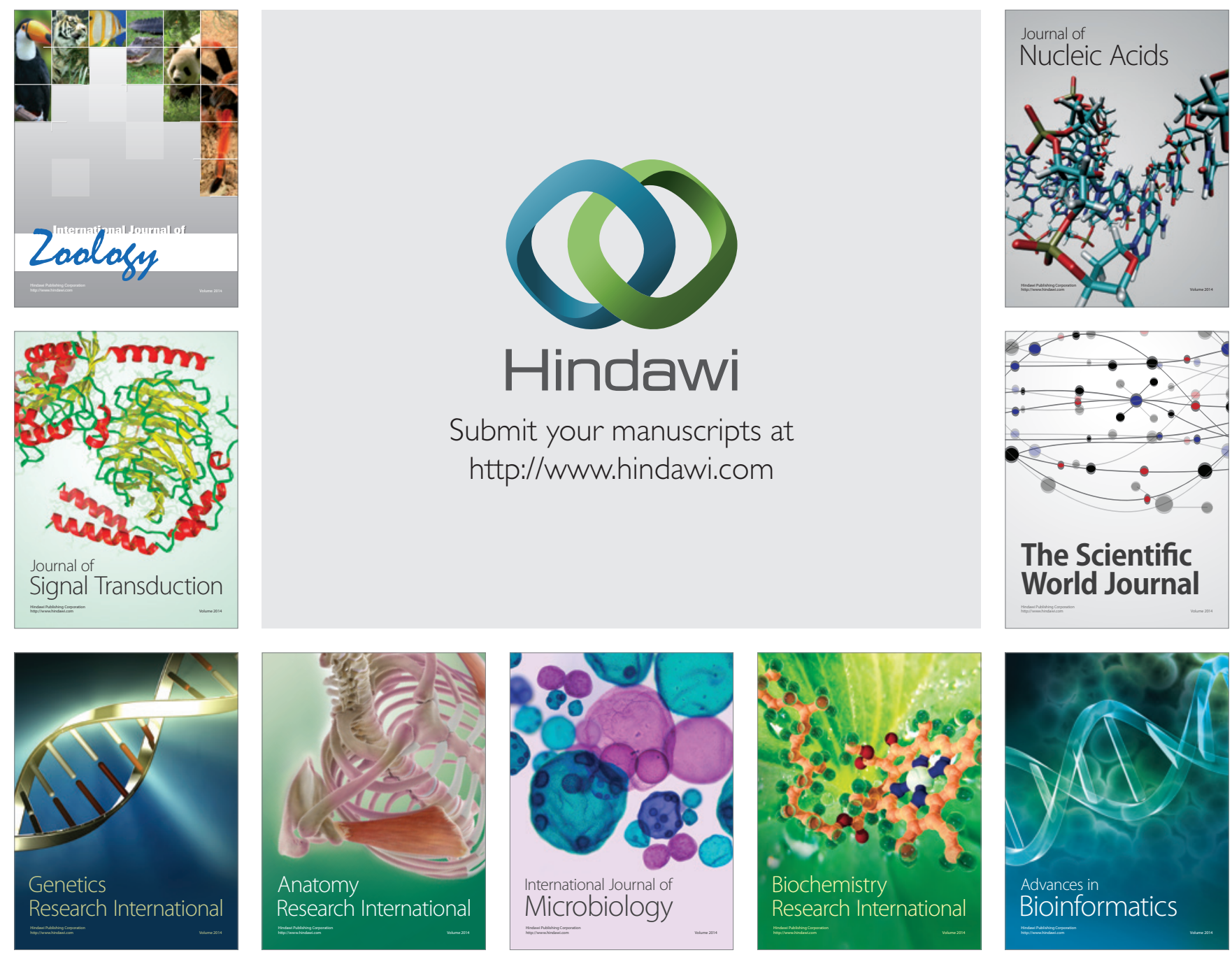

The Scientific World Journal
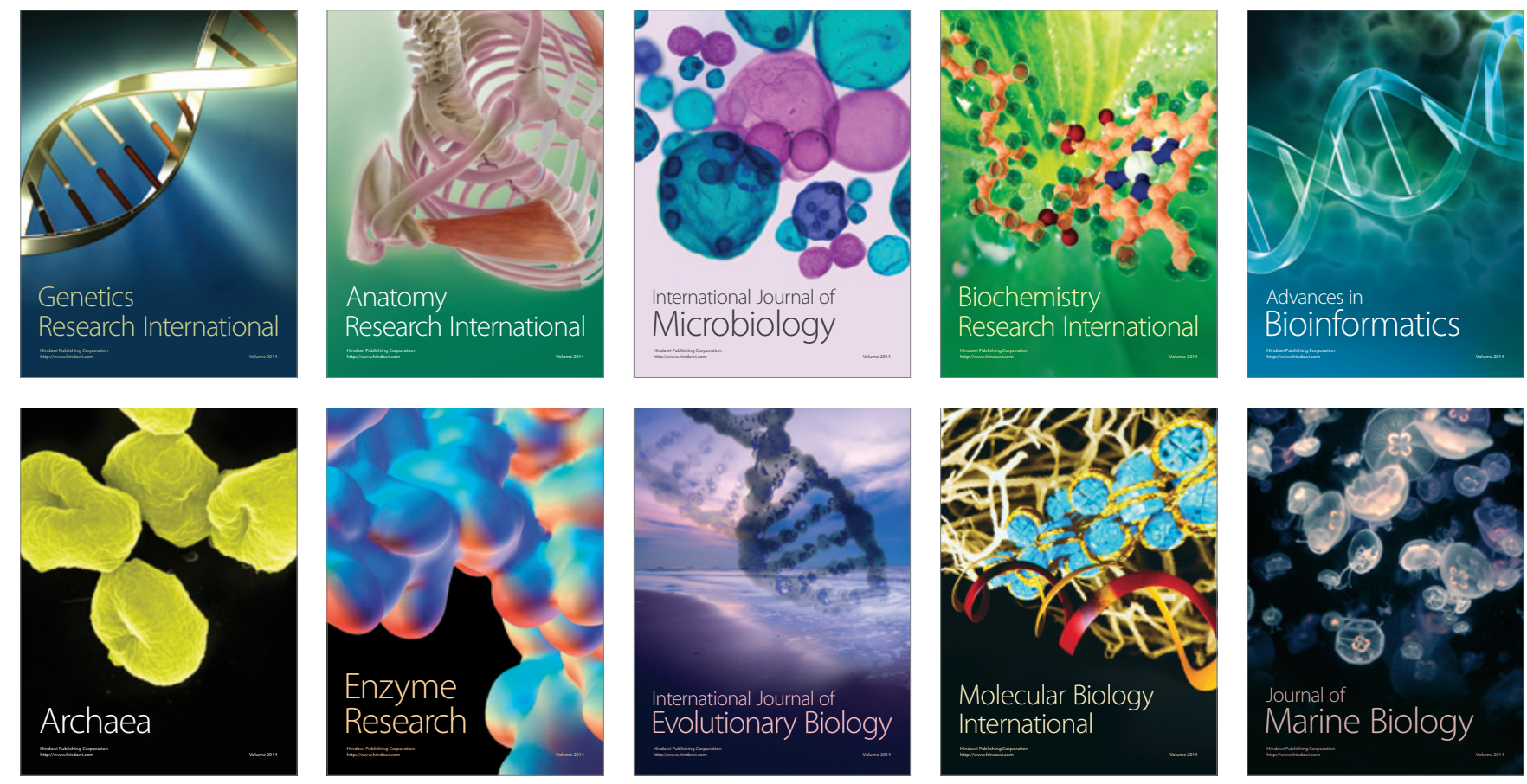